\title{
Estratégias da Psicologia para o gerenciamento de crises
}

Estrategias de la Psicología para la gestión de crisis

Psychology Strategies for Crisis Management

\author{
Maísa Hodecker \\ Centro Universitário de Brusque - Santa Catarina - Brasil
}

Roberta Borghetti Alves

Universidade Federal de Santa Catarina - Santa Catarina - Brasil

\section{RESUMO}

O gerenciamento de crises é um instrumento para identificar, obter e aplicar recursos humanos e técnicos necessários para prever, prevenir e solucionar problemáticas oriundas de uma crise. Crise é um termo designado a expressar um momento crítico, decisivo e que normalmente é sucessor de uma ruptura imprevisível do status quo. Este trabalho expressa um relato de experiência obtido através de um Estágio Específico do curso de Psicologia, no qual pretendeu-se propor estratégias de gerenciamento de crises em uma Companhia de Bombeiros Militar pertencente ao Vale do Itajaí/SC. Anterior a intervenção, aplicou-se um roteiro de entrevista semiestruturado com os sargentos militares e posteriormente, os dados foram analisados a partir da Análise de Conteúdo. Feito isso, realizou-se uma simulação do gerenciamento de crise por meio do ensaio comportamental. Constatou-se que o plano de gerenciamento de crises para ocorrências de grande vulto mais eficaz deve seguir uma lógica de procedimentos técnicos e operacionais, a saber: analisar o perímetro afetado pela emergência, organizar o local, estabelecer a segurança do local, classificar o perímetro em zona quente, morna e fria, coordenar as ações que devem ser realizadas, verificar o andamento das ações e corrigir potenciais erros, auxiliar os bombeiros a atender as afetados, encaminhar às afetados ao hospital, após o fechamento da ocorrência na COBOM, registra-la no relatório de ocorrências, e encaminhar o relatório para o tenente da corporação e à rádio. Acredita-se que bombeiros poderão aplicar este plano de gerenciamento de crises como recurso para antecipar, prevenir e resolver uma crise.

Palavras-chave: Gerenciamento de Crises. Bombeiros. Emergências. Psicologia nas Emergências.

\section{RESUMEN}

La gestión de crisis es un instrumento para identificar, obtener y aplicar recursos humanos y técnicos necesarios para predecir, prevenir y solucionar problemas originados por una crisis. La crisis es un término llamado a expresar un momento crítico, decisivo y que normalmente es sucesor de una 
ruptura imprevisible del status quo. Este trabajo expresa un relato de experiencia obtenido a través de una Etapa Específica del curso de Psicología, en el cual se pretendió proponer estrategias de gestión de crisis en una Compañía de Bomberos Militar perteneciente al Valle del Itajaí/SC. Antes de la intervención, se aplicó un guión de entrevista semiestructurado con los sargentos militares y posteriormente, los datos fueron analizados a partir del Análisis de Contenido. Hecho esto, se realizó una simulación de la gestión de crisis a través del ensayo conductual. Se constató que el plan de gestión de crisis para sucesos de gran alcance más eficaz debe seguir una lógica de procedimientos técnicos y operativos, a saber: analizar el perímetro afectado por la emergencia, organizar el local, establecer la seguridad del local, clasificar el perímetro en una zona caliente, tibia y fría, coordinar las acciones que deben realizarse, verificar el progreso de las acciones y corregir posibles errores, ayudar a los bomberos a atender a las afectadas, encaminar las afectadas al hospital, después del cierre de la ocurrencia en la COBOM, en el informe de sucesos, y encaminar el informe al teniente de la corporación ya la radio. Se cree que los bomberos pueden aplicar este plan de gestión de crisis como recurso para anticipar, prevenir y resolver una crisis.

Palabras clave: Gestión de crisis. Bomberos. Emergencias. Psicología en las emergencias.

\begin{abstract}
Crisis management is an instrument to identify, obtain and apply the human and technical resources needed to predict, prevent and solve problems arising from a crisis. Crisis is a term designed to express a critical, decisive moment that is usually the successor to an unpredictable rupture of the status quo. This work expresses an experience report obtained through a Specific Internship of Psychology course, in which it was proposed to propose crisis management strategies in a Military Fire Company belonging to the Vale do Itajaí/SC. Prior to the intervention, a semi-structured interview script was applied with the military sergeants and later, the data were analyzed from the Content Analysis. Once this was done, a crisis management simulation was performed through behavioral testing. It was found that the crisis management plan for occurrences of major magnitude more effective should follow a logic of technical and operational procedures, namely: to analyze the perimeter affected by the emergency, to organize the place, to establish the security of the place, to classify the perimeter in a warm, warm and cold zone, to coordinate the actions that must be carried out, to verify the progress of the actions and to correct potential mistakes, to assist the firemen to attend the affected ones, to send the affected ones to the hospital, after the COBOM event closes, and forward the report to the lieutenant of the corporation and to the radio. It is believed that firefighters can apply this crisis management plan as a resource to anticipate, prevent and resolve a crisis.
\end{abstract}

Keywords: Crisis Management. Firefighters. Emergencies. Psychology in Emergencies.

\section{Introdução}

Como o Corpo de Bombeiros é uma instituição prestadora de serviços no âmbito da segurança pública, e, por este motivo, está à mercê de eventos adversos e crises, optou-se por este campo para ser cenário da atuação da psicologia. Como o trabalho orientou-se no gerenciamento de crises, optou-se como principais participantes da intervenção os sargentos e sua atuação frente a equipe liderada. No Corpo de Bombeiros, o sargento possui, dentre suas atribuições, a função de chefia e liderança da guarnição durante ocorrências de grande vulto, responsável por dirigir-se ao local e organizar, com base em sua experiência, a linha de ação mais adequada para a consecução do objetivo. Ocorrências desta natureza, muitas vezes, demandam o dispêndio de uma quantidade considerável de bombeiros, energia, materiais, viaturas e que põe em risco a vida de terceiros. A 
função do sargento nessas situações é delegar funções e averiguar sua execução, visando preservar a vida dos sobreviventes e manter em segurança de sua equipe. Nestas ocasiões, é necessário que o líder possua algumas aptidões, dentre elas destacam-se a coragem, capacidade de tomar decisões rápidas, confiança, resistência física e psicológica, iniciativa, espírito de justiça, lealdade e generosidade (Passarinho, 1987; Vieira, 2002).

As possíveis contribuições da psicologia para desenvolver estratégias de gerenciamento de crises são numerosas. É possível atuar em âmbito organizacional, promoção e prevenção da saúde, tanto como público-alvo os bombeiros, como as próprias pessoas atendidas por este serviço. Tendo em visa que a Psicologia nas Emergências pauta-se na compreensão dos indivíduos antes, durante e após uma ocorrência emergencial, a atuação foi direcionada sob está perspectiva. Em outras palavras, esta área tem seu foco o estudo do comportamento de indivíduos afetados por emergências. A intervenção da Psicologia nesse contexto consiste na ação preventiva até o pós-trauma com intervenções destinadas à compreensão, ao apoio e a ressignificação do trauma. Nesse sentido, esta intervenção baseia-se em buscar métodos para prevenir e gerenciar crises emocionais causadas por situações adversas e inesperadas (Brito, 2013; Neto \&Belo, 2015; Franco, 2015).

$\mathrm{O}$ termo emergência remete-se a situações críticas, acontecimento perigoso ou danoso, caso de urgência ou incidente em que há o reconhecimento legal pelo poder público de situação anormal desencadeada por um desastre, ocasionando danos psicológicos, financeiros e/ou físicos a comunidade afetada. Além disso, a psicologia nas emergências também busca investigar como os indivíduos reagem e os efeitos em suas vidas, como a sociedade responde por meio de suas instituições e como a rede de apoio familiar influencia no processo de ajustamento ou de tratamento desta afetado (Carvalho, 2009; Franco, 2015).

Sabe-se que o oficial bombeiro lida constantemente com emergências de pequena a grande proporção, que envolvem perdas, traumas físicos e/ou psicológicos, entre outras cargas que recaem sobre seu trabalho, podendo comprometer sua própria saúde mental. Na maioria dos casos, quando há o acionamento dos bombeiros para atender uma ocorrência, dificilmente haverá um plano elaborado com antecedência para precaver possíveis agravos e danos aos afetados. A realidade é que no atendimento a uma emergência, bombeiros são destinados a cumprir alguma ação após a análise do chefe de socorro. Diante dessa problemática, o plano de gerenciamento de crises é elaborado para facilitar o atendimento e manejar as contingencias da emergência. Além disso, justifica-se a importância de implementar a psicologia nas emergências no Corpo de Bombeiros, visto que auxilia a equipe de atendimento às emergências a preparar-se psicologicamente para lidar com situações, reações e sentimentos de indivíduos que sofreram, direta ou indiretamente, danos severos e/ou alarmantes (Brito, 2013; Franco, 2015).

Muitas atividades nas emergências de grande vulto devem ser desenvolvidas de forma simultânea, entretanto podem ser organizadas em três áreas distintas: a) processo decisório; b) gerenciamento de crises e c) ações operacionais. Essas três linhas de ação, atuando de forma interativa, permitem o desenvolvimento de uma proposta pradronizada de procedimentos operacionais para o 193 Corpo de Bombeiros Militares, de forma a dotar a instituição com um plano de gerenciamento de crises para emergências de grande proporção, que seja eficiente, eficaz, integrado, participativo e exequível (Santos, 2012). 
O gerenciamento de crises consiste em um método comumente implantado em instituições de segurança pública para conduzir, resolver e conter eventoscríticos de forma rápida e eficaz. Nestes casos, parte-se do pressuposto de que a instituição deve estar preparada nos moldes do gerenciamento de crises, pois assimhaverá maiores chances de obter sucesso na administração de crises. Em instituições de segurança pública é um método indispensável, visto que os resultados das crises proporcionam prejuízos por vezes impagáveis, como a morte de pessoas ou falecimento da própria instituição devido a juízos de valor propagados pela mídia ou pela própria sociedade no que corresponde a confiabilidade da instituição de segurança (Monteiro, 2001).

Nessa direção, este trabalho pretende expressar um breve relato de experiência obtido através de um Estágio Específico do curso de Psicologia, cujo objetivo voltou-se a propor estratégias de gerenciamento de crises em uma Companhia de Bombeiros Militar pertencente ao Vale do Itajaí/SC.

\section{Procedimentos Metodológicos}

Em relação ao método, elegeu-se a modalidade de pesquisa-ação. A pesquisaação possui base empírica, caracterizando-se por uma relação direta do pesquisador com o grupo pesquisado e origina-se de necessidades sociais reais, buscando produzir transformações e ressignificações no ambiente pesquisado, baseando-se em reflexões e criações coletivas. A pesquisaação é comumente utilizada em pesquisas voltadas as áreas da educação, política, agronomia, publicidade e propaganda, assim como na área organizacional, bancária e de saúde (Gil, 2008; Grittem, Meier \&Zagonel, 2008).

\section{Procedimentos Éticos}

De antemão, o Núcleo de Prática Jurídica da instituição de ensino Centro
Universitário de Brusque - UNIFEBE formulou um contrato com a Companhia de Bombeiros Militar requerida àpotencial campo de estágio. No contrato, constavam os direitos da acadêmica estagiária e da instituição de campo, bem como as questões éticas norteadoras para a atuação de estágio. Após o consentimento por escrito do Tenente da corporação militar no contrato, realizou-se uma reunião para apresentar as propostas de intervenção e pesquisa. Consentidas, as práticas foram distribuídas em 18 encontros semestrais, sendo estes realizados semanalmente, com duração média de cinco horas no campo.

\section{Participantes}

A intervenção realizou-se em uma Companhia de Bombeiros Militar localizada na região do Vale do Itajaí/SC, que atualmente conta com o efetivo de 38 Bombeiros Militares. Dentre estes, 11 trabalham no administrativo, realizando serviços de Seções de Atividades Técnicas (SAT). Cada guarnição conta diariamente com cerca de nove profissionais militares, três Agentes da Defesa Civil e com aproximadamente $20 \quad$ Bombeiros Comunitários, que disponibilizam seu tempo nos períodos de folga para auxiliar as guarnições de serviço. Contudo, como o foco do estágio centrou-se no gerenciamento de crises, que por sua vez, é tarefa realizada comumente por sargentos e auxiliares de chefes de socorro,as intervenções ocorreram com um sargento e dois auxiliares de chefe de socorro, todos commais de 20 anos de experiência no Corpo de Bombeiros e graduação de $3^{\circ}$ sargento militar.

\section{Coleta e análise dos dados}

Para investigar os procedimentos técnicos realizados durante ocorrências de grande proporção aplicou-se um roteiro de entrevista semiestrurada. Neste roteiro continham questões direcionadas a identificação das facilidades e dificuldades enfrentadas, as preocupações, questões de segurança pública, habilidades necessárias e 
recursos humanos e técnicos disponíveis aos bombeiros militares. A partir deste instrumento foram obtidos não somente dados pertinentes ao gerenciamento de crises, mas fomentou-se a construção posterior de um plano de gerenciamento de crises para torná-lo o mais instrumentalizado possível. Além disso, a partir das informações coletadas sobre as dificuldades enfrentadas e habilidades durante $o$ gerenciamento de crises em ocorrências de grande vulto, foram formuladas questões e situações para o ensaio comportamental.

No total, foram realizados oito encontros para coletar dados por meio de entrevistas com os bombeiros. Para avaliar os dados obtidos por meio dos roteiros de entrevista semiestruturadas, optou-se pelo método de Análise de Conteúdo desenvolvido por Bardin (2004). Oriundo dos Estados Unidos por volta do século XX, logo passou a ser interesse de cientistas de diversas áreas. A Análise de Conteúdo pode ser tanto quantitativa, quando traça uma frequência das características que se repetem no conteúdo do texto ou qualitativa que considera a presença ou ausência de determinada característica na mensagem (Caregnato \&Mutti, 2006).

Em suma, Caregnato e Mutti (2006) consideram a Análise de Conteúdo como sendo uma técnica de pesquisa que trabalha com a palavra, permitindo de forma prática e objetiva produzir inferências do conteúdo da comunicação de um texto ao seu contexto social, ou seja, por meio da expressão do sujeito, a análise do conteúdo deverá categorizar unidades no texto que repetemse, denotando um tipo de expressão representativa ligada ao objetivo do estudo.

\section{Técnicas de intervenção}

\section{Observação estruturada}

Os bombeiros foram observados tanto no quartel, quanto no desempenho de funções em ocorrências no Auto Socorro de
Urgência (ASU) e Auto Bomba Tanque Resgate (ABTR). Durante a permanência no local de estágio, foram observados os bombeiros e seu comportamento diante de uma crise ou potencial crise. Já durante as ocorrências, foram observados os procedimentos realizados pelos bombeiros para gerenciar crises e/ou prevenir crises. No que concerne à observação, de acordo com Alvarez (1991), trata-se de um instrumento de pesquisa e coleta de dados que permite informar o que ocorre na realidade, na situação de fato. $\mathrm{Na}$ maioria das vezes, a observação é usada como critério para verificar a veracidade das informações obtidas através de outras técnicas, tais como entrevistas, por exemplo. O tipo de observação escolhido para fomentar a coleta de dados foi a observação estruturada, que nada mais é, a que se realiza em condições controladas para se responder a propósitos, previamente estabelecidos. Tal técnica requer planejamento e necessita de operações específicas para o seu desenvolvimento.

\section{Ensaio Comportamental}

Foram propostos dois ensaios comportamentais em momento distintos no decorrer do estágio. Um destinado a encenação do modo como é realizado o gerenciamento de crises em ocorrências de grande vulto, e outro ensaio destinado a formas possíveis de realizar o atendimento a ocorrências de grande vulto de modo mais eficaz. Foram realizados, ao todo, seis ensaios comportamentais, dois com cada sargento e chefe de socorro das guarnições. A proposta consistiu em instigá-los a encenar alguma situação real em que houve sua intervenção em meio a uma ocorrência de grande vulto e a encenação de novas maneiras de abordar os afetados na mesma condição mencionada (Souza, Orti \&Bolsoni-Silva, 2012). 


\section{Plano de Gerenciamento de Crises}

Para organizar as etapas do gerenciamento de crises, foi realizado um plano de gerenciamento em cada equipe de bombeiros. Através das observações durante as ocorrências, foram registrados os procedimentos adotados pelos bombeiros, para posteriormente analisar e organizar os dados em ordem crescente de evolução. Após esboçar um plano de gerenciamento de crises, este foi apresentado para cada sargento militar e modificado conforme necessário. $\mathrm{O}$ plano de gerenciamento levantado, após as correções, foi apresentado aos bombeiros da corporação para subsidiar uma atuação estabelecida em consenso como ideal.

O plano de gerenciamento de crises pode ser expresso como uma espécie de análise dos riscos provenientes da instauração de uma crise, que nesse sentido é a primeira fase de administração da crise, tornando-se dessa forma um planejamento operacional. O Plano de Gerenciamento de Crises é um documento planejado, elaborado e organizado a partir de estudos de uma determinada hipótese de crise, sendo consequência de uma análise dos potenciais riscos durante emergências. Como um de seus objetivos principais está voltado a prevenção, o plano de gerenciamento de crises deve ser elaborado com antecipação, previamente à situação crítica, com a discriminação de ações comuns a cada órgão, entidade ou indivíduo. Assim, o plano de gerenciamento de crises deve atentar-se e contemplar aspectos associados ao perímetro da área afetada pela crise, a organização dos materiais, o atendimento de socorro às afetados, a realização dos procedimentos de evacuação dos locais de riscos, bem como a realização de segurança para evitar agravos à situação emergencial (Coutinho, 1997).

\section{Psicoeducação}

Foi realizada a psicoeducação a respeito de novas possibilidades de intervenção em situações específicas inseridas na emergência de grande. Assim, principalmente os sargentos e chefes de socorro das guarnições foram capacitados a acolher de forma empática os bombeiros com alguma crise durante a efetivação do atendimento emergencial. Foram ensinadas formas de acolher e métodos para minimizar a ansiedade, como a prática do relaxamento através da respiração. Tal modalidade de tratamento caracteriza-se por ser limitada no tempo, estruturada, diretiva, focada no presente e na busca de resolução de um ou vários problemas, individuais e/ou organizacionais. Quando menciona-se que a psicoeducação é focada no presente, significa que as problemáticas que estão latentes e que compõe a queixa principal do usuário ou da organização são intervindas em primeiro plano. Ademais, é uma abordagem baseada em métodos experimentais e científicos, partindo do pressuposto de que as cognições gerenciam as emoções e os comportamentos. Educar o usuário é um procedimento que poderá ser executado por meio de diversas técnicas e meios, tais como: esclarecimentos, folders elucidativos, livros acessíveis a leigos, filmes, etc. Torna-se fundamental a utilização de tais técnicas, pois será por meio destas informações que o usuário aprenderá sobre o funcionamento de sua problemática, conseguindo assim, identificar comportamentos e pensamentos distorcidos e/ou disfuncionais e que podem gerar aflição e sofrimento (Figueiredo et al., 2009).

A psicoeducação, portanto, tende a envolver informações que focalizam à intervenção realizada e nos fenômenos psicológicos encontrados, educando indivíduos sobre os métodos a serem utilizados e sobre procedimentos importantes. Como a intervenção a ser realizada no Corpo de Bombeiros abordou a temática de Gerenciamento de Crises, a 
psicoeducação serviu como base para qualificar $\mathrm{o}$ atendimento emergencial prestado em ocorrências de grande vulto e o modo como sargentos militares abordam e acolhem seus subordinados em situação de crise durante o atendimento (Wright; Basco $\&$ Thase, 2008).

\section{Resultados e discussão}

Segundo as informações coletadas, uma das principais atribuições de um sargento militar em seu período de permanência do quartel é administrar o tempo e o serviço. Administrar no sentido de saber organizar as funções que devem ser executadas no dia de serviço e prever o tempo de duração para sua efetivação para que na troca de guarnição, as atividades estejam executadas com excelência. Destaca-se que no quartel existe um cronograma de atividades corporativas que devem ser executadas pela guarnição correspondente. Assim, todos os dias é realizada a limpeza de algum setor específico do quartel pela guarnição responsável, como exemplo, limpeza do pátio, da COBOM, da garagem, etc. Dessa forma, a função do sargento é analisar se a tarefa foi executada e, caso positivo, se o procedimento foi realizado da maneira correta.

Além disso, o chefe de socorro e/ou sargento militar é quem usualmente gerencia crises durante ocorrências, principalmente de grandes proporções. Para um dos entrevistados, é importante que "a equipe deve ser unida, se ajudar, assim como precisam confiar não somente em mim, mas uns nos outros" (sic). Para Armstrong (2008), uma das habilidades em lidar com uma crise é conquistar a confiança de quem está sendo liderado. Quando os subordinados confiam em quem lidera as funções, a ordem que lhes é atribuída é realizada com maior qualidade. Segundo o mesmo autor, quando os subordinados observam o líder realizando uma tarefa em meio à crise de modo não forçoso, quase relaxado, o comportamento do líder tende a refletir no comportamento dos indivíduos ao seu redor. Assim, o líder que emprega o gerenciamento de crises pode estar se esforçando ao máximo para lidar com a situação de crise, mas externamente deve demonstra aos subordinados que está controlando a situação calmamente.

Segundo a Classificação Brasileira de Ocupações (CBO) são atribuições do sargento militar inserido no Corpo de Bombeiros: prevenção de sinistros e acidentes,realizar salvamento, combater incêndios, prestar atendimento préhospitalar, controlar acidentes com produtos perigosos, comandar equipes de serviços de prontidão e chefiar guarnições. Já durante a execução de atividades, o bombeiro necessitará ser ágil e eficaz no que tange a comunicação, tanto para atender ocorrências como para tranquilizar vítimas e orientar a população. Cabe mencionar que o Regulamento Interno e de Serviços Gerais (RISG) estabelece que mediante adequação de nomenclaturas e peculiaridades do serviço, prevê que o Sargento é o auxiliar do fiscal do dia de serviço. O serviço de fiscal numa unidade operacional do Corpo de Bombeiro deverá ser executado prioritariamente por um Sargento. O auxiliar do chefe de socorro do dia responde pelas funções do chefe de socorro no período em que este estiver ausente da unidade.

Além disso, diariamente as ocorrências atendidas pela COBOM são registradas e computadas a fim de que sejam elaborados relatórios a serem encaminhados para a rádio da cidade e para o Tenente. Para a rádio, o relatório de ocorrências é repassado para fins de divulgação de mídia. Já para o tenente, o relatório das ocorrências fornece subsídios para reconhecer a necessidade da aquisição de novos materiais, equipamentos e/ou viaturas, de acordo com a demanda atendida. Este relatório é elaborado pelo sargento e pelo bombeiro que registrou a ocorrência na COBOM, contendo informações sobre o 
estado em que a vítima encontrava-se na ocorrência, os procedimentos realizados e como foi sucedida a ocorrência (se houve ou não o encaminhamento da vítima para a unidade hospitalar).

Já durante uma ocorrência de grande vulto, a função do sargento é acompanhar o andamento da ocorrência de forma ampla. Assim, o sargento deve analisar a ocorrência e as ações realizadas por cada bombeiro de sua guarnição, visando a segurança dos bombeiros e da vítima. Durante uma ocorrência de grande vulto o sargento é encarregado de realizar em um curto período de tempo diversas funções, desde realizar o gerenciamento de crises, delegar funções, classificar e estabelecer segurança no perímetro, até a retirar de fotos para divulgação e registro no relatório de ocorrências.

Para propor estratégias de gerenciamento de crises, foram realizadas observações estruturadas no quartel e entrevistas semiestrururadas com os sargentos militares e chefes de socorro de cada guarnição, simulações com sargentos militares por meio do ensaio comportamental e, simultaneamente, foi construído um plano de gerenciamento de crises. O gerenciamento de crises consiste no planejamento de uma ação que visa identificar, obter e aplicar recursos necessários à antecipação, prevenção e resolução de uma crise. A proposta consistiu em que os sargentos simulassem uma ocorrência de grande vulto, relatassem os comportamentos e reações que de praxe são realizados e fosse estruturado um plano de gerenciamento que poderia ser adaptado para outras ocorrências conforme a necessidade da demanda (Thomé \&Salignac, 2001).

O termo gerenciamento de crises foi criado por Robert Macnamara durante a época da crise dos mísseis cubanos assim que mencionou "não existe mais estratégia, só gerenciamento de crise". A expressão abarca conteúdos utilizados nos círculos diplomáticos, mas é algo corriqueiro em organizações cuja pressão dos eventos internos e externos força a gerência a tomar decisões urgentes. Sobretudo, o gerenciamento de crises pode ser caracterizado como o processo de lidar com uma situação de alta pressão de forma a planejar, organizar, dirigir e controlar várias operações inter-relacionadas, orientando o processo de tomada de decisões para atingir uma resolução rápida e eficaz (Armstrong, 2008).

$\mathrm{Na}$ simulação os sargentos expressaram que o primeiro passo para $o$ gerenciamento de crises adaptado ao contexto do bombeiro militar é analisar a ocorrência de forma ampla e generalista. Devem-se analisar todo perímetro da ocorrência e, feito isso, estabelecer as zonas que devem ser intervindas em um primeiro plano. Tendo em vista que cada bombeiro já possui sua função pré-estabelecida, os sargentos relataram que delegar funções, nestes casos, será realizado somente se algum dos bombeiros for observado com alguma dificuldade diante da função que está executando. Após, classifica-se o perímetro em zonas: quente, morna e fria. A zona quente trata-se do espaço onde a ocorrência foi estabelecida, isto é, local que sofreu mais intensamente os efeitos do evento que causou a situação crítica local e onde os bombeiros estão concentrados para amenizar a situação. É nessa área que serão desenvolvidas as operações de maior risco e complexidade. A zona morna é o perímetro ainda restrito para a terceiros, mas as condições de risco não são tão altas quanto na zona anterior, sendo caracterizado como uma área propicia para que os profissionais se equipem, repassem informações e realizem as últimas verificações de segurança antes de adentrar na zona quente novamente. A zona fria é o local que a comunidade se encontra e fora de perigo eminente. Além disso, a zona fria abriga instalações e recursos que poderão dar suporte as atividades técnicas. Durante os procedimentos pré-hospitalares, os sargentos 
verificam a qualidade do atendimento, e, caso necessário, é realizado a orientação ao subordinado de outro modo de realizar o procedimento. Caso o sargento analise que o procedimento foi realizado corretamente, os bombeiros deslocam a afetado para $o$ hospital, no qual irá receber o atendimento especifico e necessário para sua demanda. Ao chegar no quartel novamente, a ocorrência é registrada na COBOM, e, posteriormente, o sargento confecciona um relatório contendo as ocorrências atendidas durante o dia, especificando o caso. $\mathrm{O}$ procedimento final é encaminhar este relatório para a rádio e para o Tenente.

Em relação aos materiais utilizados durante a ocorrência, após o retorno para o quartel e, de preferência, antes da troca de guarnição, as narrativas dos bombeiros apontam que é realizada a checagem de todos os equipamentos da zona morna, assim como o sargento sugere: "Fazemos a verificação dos materiais e ferramentas na zona morna, que fica entre a quente e fria. A área morna já está em maior segurança, então permite que o bombeiro pense e aja melhor" (sic). Feita a verificação dos materiais, é realizada a limpeza dos mesmos e higienização da viatura. De acordo com os relatos, o profissional responsável pela limpeza da viatura costuma ser realizada pelo bombeiro motorista e um auxiliar. Caso seja verificado algum dano ou falta de equipamento na viatura, as informações são repassadas ao sargento chefe de socorro que irá solicitar a compra de um novo material.

Em relação as crises, foram observadas crises durante o atendimento a ocorrências de grandes proporções, em que vítimas atendidas não conseguiam lidar com os traumas sofridos. Já no que concerne aos bombeiros, as crises se originavam com maior frequência diante do atendimento às ocorrências envolvendo vítimas infantis. Os entrevistados justificam essa problemática do bombeiro em relação as crianças devido a "todos os bombeiros daqui, ou quase todos, têm filhos, então a tendência é você se colocar no lugar desse pai e mãe, e sofrer junto com o trauma da criança" (sic). Crises são eventos comumente desencadeados por um desastre imprevisível que acarreta prejuízos à vida do indivíduo. Como o Corpo de Bombeiros é um órgão de segurança pública sujeito a presenciar cenas que podem, muitas vezes, desencadear crises até mesmo nos profissionais que prestam o atendimento, é necessário conter na guarnição um líder capaz de delegar funções e apoiar a equipe quando necessário. Visto que a desordem mental é um dos sintomas mais presentes durante uma crise, torna-se necessário a presença de um líder para orientar o afetado a sair desse estado de desordem e ofertar suporte emocional até que se perceba o restabelecimento do equilíbrio (Armstrong, 2008).

Dentre as maiores crises que os bombeiros entrevistados já atenderam, destacam-se as crises decorrentes de transtornos psicológicos, mortes de algum membro da família e tentativa de suicídio. Franco (2015) afirma que devido as crises vivenciadas pela sociedade, têm-se confirmado a necessidade cada vez maior do refinamento das instituições de segurança pública. Pela abrangência e complexidade em que o gerenciamento de crises se apresenta, faz-se necessário por parte das instituições uma formação e destrezas especiais, profissionais que acolham perfis peculiares para cada atividade desenvolvida no palco de operações.

Em relação ao gerenciamento de crises em que o afetado é o próprio bombeiro que presta $o$ atendimento a ocorrência, a técnica comumente empregada para amenizar a situação e dar suporte aos bombeiros de sua equipe é o acolhimento individual ou, caso mais bombeiros estejam com sofrimento psíquico aparente, são realizadas reuniões para que possam expor seus sentimentos e traumas sofridos através da ocorrência atendida. Segundo relatos, procura-se ofertar um espaço para que os dilemas sejam enfrentados e compartilhados 
com a própria equipe, visando não somente minimizar o sofrimento, mas também a troca de experiência e apoio da equipe, estreitando o vínculo entre sargento e equipe. Para um dos chefes de socorro, o gerenciamento de crises é feito tanto no interior, quanto no interior da corporação militar: "gerenciamos crises emocionais, físicas, fisiológicas, que rompem o mundo presumido da vítima, causando intensa dor e sofrimento" ( $\mathrm{sic}$ ). Gerenciamento de crise é o processo eficaz de se identificar, obter e aplicar, de conformidade com a legislação vigente e com emprego das técnicas especializadas, os recursos estratégicos adequados para a resolução da crise. As estratégias de contenção da crise podem ser medidas de antecipação, prevenção e/ou de resolução, visando assegurar o completo restabelecimento da ordem pública e da normalidade da situação. Especificamente em ocorrências em que a atuação será do Bombeiro Militar faz-se necessária, o aparecimento de uma crise é muito provável, especialmente em situações em que a vida de vários indivíduos está em risco (Thomé \&Salignac, 2001).

Contudo, através das observações estruturadas foi possível averiguar que a periodicidade dos bombeiros apresentarem alguma queixa relacionada a ocorrências é maior do que a ocorrência de reuniões. Em um período de seis meses de estágio, uma reunião foi presenciada, mas seu assunto não era direcionado as ocorrências e seus aspectos psicológicos. Verificou-se durante as observações que ocorrências envolvendo crianças são as que mais proporcionam problemas de ordem psicológica aos bombeiros. Fica evidente não somente a necessidade de acompanhamento psicológico contínuo a esses profissionais, como uma preparação teórica e prática permanente aos sargentos visando a manutenção da saúde psicológica dos bombeiros. Para devolver esta constatação a corporação militar, foi necessário realizar uma reunião com a equipe de bombeiros, bem como com o tenente da corporação.
Todos os entrevistados salientaram a importância de haver reuniões semanais para dialogar sobre as ocorrências, sobre questões psicológicas circundadas pelas ocorrências e aspectos pessoais relevantes de cada bombeiro. Vê-se a importância da troca de experiencias e saberes em reuniões perante a fala: "trabalho com bombeiros aqui há mais de 10 anos, que não sei nada sobre a vida deles pessoal, nem os dilemas que enfrentam em casa ou durante uma ocorrência" (sic).

Em relação às dificuldades encontradas, observou-se que a maioria dos bombeiros não somente trabalha formalmente na corporação durante 24 horas, mas, nos períodos de folga, isto é, 48 horas, tendem a realizar algum trabalho informal para complementar a renda familiar. Segundo as narrativas dos entrevistados, acredita-se que tal ato tende a sobrecarregar ainda mais o bombeiro, tendo em vista que o efetivo já está desfalcado e no quartel há um acúmulo de funções para cada bombeiro. Em relação ao aspecto salarial do bombeiro, um dos chefes de socorro afirma que " $O$ salário é bom, mas poderia ser ainda melhor para que pais de família não precisassem de bicos para se manter" (sic). Em contrapartida, outro entrevistado destacou que o correto seria que os bombeiros administrassem seu tempo para separar um tempo de lazer e descanso, esforçando-se somente na organização: " $o$ salário é capaz de suprir todas as necessidades de uma pessoa, se eles se organizassem melhor, não precisavam trabalhar fora e virem cansados para cá" (sic). Diante disso, Monteiro et al. (2007) expõe que a dificuldade encontrada no bombeiro exercer um trabalho formal e outros informais em seu período de folha está justamente na sobrecarga de trabalho que isso gera, aspecto também mencionado pelos sargentos nas entrevistas, pois nas horas destinadas ao descanso, à convivência familiar, ao relaxamento para o próximo dia de trabalho, o bombeiro está em outro trabalho. Assim, não há um momento 
destinado ao descanso, e, no retorno ao quartel, as pressões parecem se tornar ainda maiores.

Através das entrevistas, foi possível analisar que há bombeiros que certificam que o salário é incompatível com a função desempenhada, tendo em vista que sua vida é posta a riscos eminentes constantemente. Contudo, justificam a necessidade de ter outros meios de trabalho o custo alto de vida que possuem, a família e desejo por adquirir bens materiais. Em contrapartida, outros bombeiros acreditam que o salário é ideal, sem necessidade de realizar trabalhos extras. Além dos fatores externos mencionados, há fatores internos narrados por bombeiros que contribuem para a busca de trabalhos extras nos períodos de folga, como a inquietação e a ansiedade. Para ilustrar tal afirmação, um bombeiro descreve que "a gente fica aqui [quartel], eufórico esperando uma chamada. Quando está em casa, a gente nem desliga. Toca o telefone, um alarme e já começa a inquietação, a ansiedade" (sic). Durante as entrevistas, foi possível analisar que os bombeiros associam o cotidiano frenético de tarefas a ansiedade que possuem nos períodos de folga. Há um salto de ativação corporal no cotidiano dos bombeiros: euforia no trabalho de bombeiro e ansiedade nos períodos de folga.

Outro fator mencionado pelos sargentos como um fator que desestimula a atuação profissional, abarca questões relacionadas as intrigas da equipe devido ao repasse de informações pessoais e profissionais que denigrem sua imagem. Para os sargentos, muitas informações são alteradas e repassadas erroneamente entre a equipe de bombeiros, e, consequentemente, causam um sentimento de desmotivação e desrealização com o trabalho. Diante disso, um dos sargentos mencionou que "um dos sargentos deixa os bombeiros da equipe dele fazer triagem pelo telefone. Meus bombeiros foram alertados de que poderiam também, mas não autorizei" (sic). Outro relato de um sargento sugere que estas informações tendem a influir sobre o ânimo e relacionamento da equipe: "a maioria dos bombeiros fala que sou autoritário, e isso acaba me desestruturando e desanima" (sic).Esta problemática exige destes profissionais adotar uma postura de mediadores, tentando resolver os conflitos em prol da qualidade do atendimento e da relação interpessoal com a equipe de trabalho.

Uma vez instalada a crise, esta exigirá dos órgãos que compõem o Sistema de Defesa Social do Estado, como Polícia Militar e Corpo de Bombeiros, uma resposta imediata para enfrentar o acontecimento e evitar maiores danos aos envolvidos que acontecerá, por sua vez, por meio do gerenciamento de crises. O Gerenciamento de Crises caracteriza-se por ser um processo racional e analítico de resolver problemas baseados em probabilidades. Gerenciar crises é uma tarefa que busca a resolução de problemas com base em possibilidades. Porém, é fundamental avaliar que não é uma ciência exata, ou um método instantâneo e de simples solução. Cada crise apresentarse-á de atributos únicos, e isto irá demandar do profissional atuante soluções distintas que exigem cuidadosa análise e reflexão (Castro, 1998).

Observou-se durante as ocorrências que para gerenciar uma crise é necessário elencar quais os problemas presentes na situação. Posteriormente, são avaliados e denominados como problemas primários, secundários e terciários. Os problemas primários são aqueles em que pretende-se eliminar em um primeiro plano. Assim, classifica-se a importância de sua eliminação em ordem crescente. A lógica do gerenciamento de crises é manter a concentração em um problema mais emergente e evitar que a situação se agrave para uma crise (Thomé \&Salignac, 2001; Armstrong, 2008).

Ainda conforme as entrevistas, o gerenciamento de crises auxilia o bombeiro 
a atuar de forma rápida e eficaz, tendo como principal objetivo a preservação da vida dos envolvidos na ocorrência. Brito (2002) corrobora afirmando que o gerenciamento de crises do Bombeiro Militar tem como objetivo superior, em absoluta observância dos valores predominantes, a preservação da vida. O comandante de uma ocorrência de crise deve estar consciente de tal objetivo, mesmo que, a opção de preservar vidas, possa contribuir para uma momentânea fuga dos elementos antes planejados. O impasse que é estabelecido no gerenciamento de crises se dá pela distinção entre estas situações e as ocorrências atendidas rotineiramente no quartel. Apesar do bombeiro lidar constantemente com ocorrências que apresentam complexidade e impacto, estes eventos não podem ser gerenciados adequadamente somente com a aquisição de mais pessoal e material. Há a necessidade de novas respostas, mudança da estrutura das organizações abarcadas, mobilização de pessoas que não respondem ordinariamente a estes órgãos, além de várias outras providências para a solução aceitável da crise.

Em outras palavras, o gerenciamento de crises pode ser descrito como uma metodologia que emprega, muitas vezes, uma sequência lógica de ações direcionadas a resolução de problemas, fundamentandose em possibilidades. Tendo em vista que cada crise possui características particulares, o gerenciamento de crises não é uma ciência exata, exigindo que soluções sejam tomadas após uma cuidadosa análise e reflexão da situação. Portanto, o gerenciamento de crises é o processo de identificar, obter e aplicar os recursos necessários à antecipação, prevenção e resolução de uma crise (Chiavenato, 1994).

Observou-se que o gerenciamento de crises é praticado principalmente em ocorrências de grandes proporções, onde há maiores vítimas e os procedimentos de resgate/salvamento/socorro são mais complexos. Thomé e Salignac (2001) confirmam que crises são ocorrências de gravidade e magnitude que podem acarretar mortos, feridos, prejuízos materiais, desgaste do Governo e aos organismos envolvidos se não forem gerenciadas adequadamente. Geralmente manifesta-se de maneira súbita, inesperada, requer resposta imediata, coordenada e efetiva de vários órgãos governamentais e privados. Comumente envolve muitas pessoas prejudicas pelo evento em um mesmo ambiente, contemplada de maneira usualmente caótica. Nestes casos, o profissional deve estar preparado para realizar tarefas complexas em tempo e ritmo intensos, até que a crise perca intensidade.

Verificou-se através dos relatos que o gerenciamento de crises é útil principalmente para a manutenção do controle da ocorrência. O gerenciamento de crises começa evitando ações impulsivas e mantendo o controle da situação para evitar seu agravamento. As ações do líder são, em sua maioria, de natureza preventiva para minimizar danos aos indivíduos envolvidos. De modo geral, o maior talento de um líder está em sua capacidade de acelerar o processo de tomada de decisões para a resolução do problema. Um gerenciamento de crises baseia-se em definir a situação, especificar objetivos, desenvolver hipóteses, coletar fatos, analisar os fatos, considerar possíveis cursos de ação e avalia-los, decidir, implantar e monitorar sua implantação (Armstrong, 2008).

De modo geral, o gerenciamento de crises, método casualmente utilizado pela Polícia Militar, consiste no processo de identificar, obter e aplicar os recursos necessários à resolução de uma crise. Tratase de um conjunto de preceitos e princípios doutrinários que permitirão gerenciar, em uma situação de crise, os mais complexos problemas, dentre eles destacam-se os sociais e psicológicos em momentos críticos e quando todos eles manifestam-se em termos destrutivos. O Gerenciamento de crise não é uma ciência exata ou um 
processo rápido de fácil resolução de problemas. Cada crise apresenta características singulares, exigindo soluções individualizadas, que demandam cuidadosa análise e reflexão (Armstrong, 2008).

Assim, o processo de administração das ações deve incluir o teatro das operações. Durante este procedimento, devem-se operar algumas sequências de procedimentos. Primeiramente, para conter a crise é necessário adotar medidas para evitar que a situação se alastre. Após, deve-se analisar e isolar o ponto crítico, estabelecendo os perímetros de segurança. Feito isso, deve-se estabilizar a situação, isto é, propiciar um clima de segurança e equilíbrio nos momentos iniciais da ocorrência, tranquilizando os ânimos, emoções e tensões dos atores da ocorrência. Por fim, organizar as tarefas que devem ser realizadas e delegá-las aos profissionais que ali atuam (Thomé \&Salignac, 2001).

\section{Considerações finais}

Como visto no decorrer deste trabalho, pretendeu-se propor estratégias de gerenciamento de crises no âmbito do Corpo de Bombeiro Militar. Percebe-se que, de início, não foi estabelecida a natureza emergencial a qual seria destinada, embora fosse acordado durante o estágio que, tendo em vista a complexidade do atendimento, o gerenciamento de crises seria explanado com ênfase em atendimento emergencial em ocorrências de grande proporção. Tendo estabelecido este critério, buscou-se intervenções que respondessem a problemática a longo prazo. Assim, a intervenção foi classificada em três etapas gerais: coleta de dados, análise dos dados e formalização dos dados obtidos em relatório. Para coletar os dados, optou-se pela observação estruturada e pela realização de um roteiro de entrevista semiestruturada. De maneira geral, a observação proporcionou a estagiaria não somente compreender a dinâmica organizacional do trabalho dos bombeiros militares, mas fomentou a construção do roteiro de entrevista semiestruturada, possibilitando que fosse direcionada a realidade dos bombeiros diante das emergências mais recorrentes que prestam atendimento. Para intervir, buscou-se engajar os bombeiros por meio do ensaio comportamental na realização de simulações de ocorrências, demonstrando seus respectivos comportamentos e ações realizadas para suprir a demanda. A partir da encenação, foi construído um plano de gerenciamento de crises para emergências de grande vulto. Além disso, de modo intercalar, foi realizada a psicoeducação a respeito de novas possibilidades de intervenção em situações especificas inseridas na emergência de grande, por exemplo, como se portar diante de um bombeiro em crise. Assim, principalmente os sargentos e chefes de socorro das guarnições foram capacitados a acolher de forma empática os bombeiros com alguma crise durante a efetivação do atendimento emergencial.

Como dito, o plano de gerenciamento de crises elaborado constituise dos seguintes passos durante uma ocorrência de grande vulto: 1) analisar o perímetro; 2) organizar o local; 3) fazer a segurança do local; 4) classificar o perímetro em zona quente, morna e fria; 5) coordenar as ações que devem ser realizadas; 6) verificar o andamento das ações e corrigir erros; 7) auxiliar os subordinados a atender as afetados; 8) encaminhar as afetados ao hospital; 9) após o fechamento da ocorrência na COBOM, registra-la no relatório de ocorrências diárias; e 10) encaminhar o relatório de ocorrências para o tenente da corporação e para a rádio.

Nesse sentido, constatou-se por meio das entrevistas que uma das maiores dificuldades existentes em exercer um cargo de chefia nestas organizações militares diz respeito a administração de conflitos entre a equipe de subordinados após o atendimento emergencial. Constatou-se que existem 
conflitos no ambiente laboral, bem como afirmaram que o profissional responsável por resolver os conflitos comumente é o líder. Para tal, normalmente empregam as reuniões e conversas individuais com os participantes do conflito para tentar compreender a situação e amenizar os danos. Pode-se observar que os conflitos interpessoais foi o aspecto mais mencionado nas entrevistas, e que os conflitos verticais e horizontais, ou seja, os de nível hierárquico iguais e diferentes estão representados igualmente. Ademais, notou-se que quando ocorrem conflitos esses repercutem entre todos $\mathrm{e}$ influenciam sobre $\mathrm{o}$ trabalho desempenhado no quartel e até mesmo na qualidade do atendimento ao público.

A partir do que foi exposto, sugerese intervenções voltadas ao fortalecimento das relações interpessoais entre a equipe e desenvolvimento de habilidades sociais, como exemplo disso, pode-se citar a assertividade, empatia e a resiliência. Além disso, sugere-se intervenções de educação permanente para capacitar os bombeiros a atuar de modo eficaz frente a demanda infantil, visto a dificuldade encontrada por diversos bombeiros em prestar atendimento a afetados infantis. A nível qualitativo, sugere-se pesquisas voltadas a investigação da qualidade de vida do profissional bombeiro, devido ao estresse analisado no período pós-traumático. Ainda sobre pesquisas qualitativas, sugere-se a avaliação destes profissionais quanto a depressão e a Síndrome de Burnout, visando estabelecer um potencial nexo causal com a atividade laboral realizada pelo bombeiro.

\section{Referências}

Alvarez, M. E. B.(1991). Organização, Sistemas e Métodos. São Paulo: McGraw Hill.

Armstrong, M.(2008). Como ser um gerente melhor: técnicas provadas de $\mathrm{A}-\mathrm{Z}$ sobre as habilidades essenciais que todo gerente precisa ter. (3. ed.). São Paulo: Clio Editora.
Brito, J., \&Fontes, N. (2002). Estratégias para eventos: uma ótica do marketing e do turismo. São Paulo: Aleph.

Brito, C. C. de. (2013). A importância da inclusão da Psicologia das Emergências no curso de formação de oficiais. 2013. $21 \mathrm{f}$. Artigo Monógrafo (Curso de Formação de Oficiais) - Academia Bombeiro Militar, Goiânia.

Carvalho, A. C. de A. (2009). A trajetória histórica e as possíveis práticas de intervenção do psicólogo frente às emergências e aos desastres. $2009.51 \mathrm{f}$. Monografia (Bacharel em Psicologia) Universidade do Vale do Itajaí, Biguaçu.

Castro, A. L. C. (1998). Glossário de defesa civil estudos de riscos e medicina de desastres. 2.ed. Brasília: Imprensa Nacional.

Caregnato, R. C. A., \&Mutti, R. (2006). Pesquisa qualitativa: análise de discurso versus análise de conteúdo. Texto contexto - enfermagem, Florianópolis, v. 15, n. 4, p. 679-684, Dez. Recuperado em 09 de maio de 2017, de

http://www.scielo.br/scielo.php?script=sc i_arttext\&pid=S010407072006000400017\&lng=en\&nrm=iso.

Chiavenato, I. (1994). Gerenciando pessoas: o passo decisivo para a administração participativa. 2. ed. São Paulo: Makron Books.

Coutinho, S. A. de A.(1997). Exército do comando: a chefia e a liderança militares. Rio de Janeiro: Biblioteca do Exército.

Figueiredo, A. L. de, et al. (2009). O uso da psicoeducação no tratamento do transtorno bipolar. Revista Brasileira de Terapia Comportamental Cognitiva, São Paulo, v. 11, n. 1, p. 15-24, Jun.

Recuperado em 01 de dezembro de 2016, de

http://pepsic.bvsalud.org/scielo.php?scrip $\mathrm{t}=\mathrm{sci}$ arttext\&pid=S1517$\underline{55452009000100003 \& \operatorname{lng}}=\mathrm{pt} \& \mathrm{nrm}=\mathrm{iso}$

Franco, M. H. P.(2015). Intervenção

Psicológica em Emergências:

Fundamentos para a prática. São Paulo: Summus.

Gil, A. C.(2008). Como elaborar projetos de 
pesquisa.(4. ed.). São Paulo: Atlas.

Grittem, L.,Meier, M. J., \&Zagonel, I. P. S. (2008). Pesquisa-ação: uma alternativa metodológica para pesquisa em enfermagem. Texto contexto enfermagem, Florianópolis, v. 17, n. 4, p. 765-770, Dez. Recuperado em 20 de fevereiro de 2017, de http://www.scielo.br/scielo.php?script=sc i_arttext\&pid=S010407072008000400019\&lng=en\&nrm=iso

Monteiro, R. das C. (2001). Curso de Controle e Resolução de Conflitos e Situações de Crises Curso - Ministério da Justiça. Academia Nacional de Polícia.

Departamento de Polícia Federal. Brasília.

Monteiro, J. K., et al.(2007). Bombeiros: um olhar sobre a qualidade de vida no trabalho. Psicologia: ciência e profissão, Brasília, v. 27, n. 3, p. 554565 , Set. Recuperado em 26 de novembro de 2016, de http://pepsic.bvsalud.org/scielo.php?scrip $\mathrm{t}=$ sci_arttext\&pid=S141498932007000300014\&lng=pt\&nrm=iso

Neto, O. D., \&Belo, F. R. R. (2015). Psicologia das Emergências. Belo Horizonte, Gerais: Revista Interinstitucional de Psicologia,v. 8, n. 2, Edição Especial, p. 284-299, Dez. Recuperado em 26 de fevereiro de 2017 , de

http://www.fafich.ufmg.br/gerais/index.p hp/gerais/article/viewFile/565/386

Passarinho, J. G. (1987). Liderança Militar. Rio de Janeiro: Biblioteca do Exército, 1987.

Santos, T. G. dos. (2012). Liderança e trabalho em equipe: virtudes importantes na carreira do bombeiro militar. Curso de Formação de Soldados. Biblioteca CEBM/SC, Florianópolis. Recuperado em 04 de junho de 2017, de https://biblioteca.cbm.sc.gov.br/bibliotec a/index.php/component/docman/doc_do wnload/244-thayse-gabriela-dos-santos

Souza, V. B. de, Orti, N. P., \&Bolsoni-Silva, A. T. (2012). Role-playing como estratégia facilitadora da análise funcional em contexto clínico. Revista brasileira de terapia comportamental e cognitiva, São Paulo, v. 14, n. 3, p. 102122, dez. Recuperado em 10 de junho de 2017, de

http://pepsic.bvsalud.org/scielo.php?scrip $\mathrm{t}=$ sci_arttext\&pid=S151755452012000300006\&lng=pt\&nrm=iso

Thomé, R. L., \&Salignac, A. O. (2001). $O$ gerenciamento das situações policiais críticas. Curitiba: Genesis.

Vieira, B. (2002). Liderança Militar. Academia Militar. Estado Maior do Exército.

Wright, J. H., Basco, M. R., \&Thase, M. E. (2008). Aprendendo a terapia cognitivocomportamental: um guia ilustrado. Porto Alegre: Artmed.

Dados sobre as autoras:

- Maísa Hodecker é acadêmica da $10^{\mathrm{a}}$ fase do Curso de Psicologia do Centro Universitário de Brusque - UNIFEBE.

- Roberta Borghetti Alves é doutoranda em Psicologia pela Universidade Federal de Santa Catarina. Mestre em Psicologia pela Universidade Federal de Santa Catarina. Membro da Comissão Nacional de Psicologia nas Emergências e Desastres do Conselho Federal de Psicologia. Formou-se em Psicologia pela Universidade do Vale do Itajaí. No decorrer da sua trajetória acadêmica participou como bolsista do Projeto de Extensão Univali Mulher. Além disso, foi bolsista do PET Saúde (Programa de Educação para o trabalho em Saúde). Em 2011 participou da Operação Especial pelo Projeto Rondon no Rio Paraguai, atuando com educação ambiental, saúde e desenvolvimento sustentável com comunidades ribeirinhas. 